of time, the highest numbers of signals were detected by $\mathrm{FOI}$ with $32 \%$ of joints, especially in phase 2 while by US/PD $20.7 \%$ and by clinical examination $17.5 \%$ were active. A high number of joints $(21.1 \%)$ had FOI signals but were clinically inactive. $20.1 \%$ of joints with signals in $\mathrm{FOI}$ did not show effusion, synovial thickening or hyperperfusion by US/PD. Due to the high number of negative results specificity of FOI compared to clinical examination/US/PD was high (84-95\%), sensitivity was moderate only.

Conclusions: Improvement upon treatment with either methotrexate or a biologic can be visualized by FOI. FOI and US/PD could detect clinical but also subclinical inflammation. FOI detected subclinical inflammation in higher extent than US. Disclosure of Interest: None declared

DOI: 10.1136/annrheumdis-2017-eular.2293

\section{OP0058 IMPROVEMENT IN PATIENT-REPORTED OUTCOMES IN PATIENTS WITH POLYARTICULAR-COURSE JUVENILE IDIOPATHIC ARTHRITIS AND INADEQUATE RESPONSE TO BIOLOGIC OR NON-BIOLOGIC DISEASE-MODIFYING ANTIRHEUMATIC DRUGS TREATED WITH SC ABATACEPT}

N. Ruperto ${ }^{1}$, H. Brunner ${ }^{2}$, N. Tzaribachev ${ }^{1}$, G. Vega-Cornejo ${ }^{1}$, I. Louw ${ }^{1}$, J. Anton ${ }^{1}$, D. Viola ${ }^{1}$, I. Foeldvari ${ }^{1}$, V. Keltsev ${ }^{1}$, D. Kingsbury ${ }^{2}$, C. Wouters ${ }^{1}$, B. Lauwerys ${ }^{1}$, E. Alemao ${ }^{3}$, R. Wong ${ }^{3}$, M. Nys ${ }^{4}$, S. Banerjee ${ }^{3}$, A. Martini ${ }^{1}$ D. Lovell $2 .{ }^{1}$ PRINTO, Istituto Gaslini, Genoa, Italy; ${ }^{2}$ PRCSG, CHMC, Cincinnati; ${ }^{3}$ Bristol-Myers Squibb, Princeton, United States; ${ }^{4}$ Bristol-Myers Squibb, Braine L'Alleud, Belgium

Background: In patients (pts) with polyarticular-course juvenile idiopathic arthritis (pJIA), SC abatacept (ABA) $125 \mathrm{mg}$ weekly has a similar pharmacokinetic profile, therapeutically equivalent efficacy and comparable safety to IV ABA $10 \mathrm{mg} / \mathrm{kg}$ every 4 weeks. ${ }^{1}$ Although some data on paediatric pt-reported outcomes (PRO) have been published for IV ABA, ${ }^{2}$ PRO data following treatment with SC ABA have not.

Objectives: This analysis examined the effect of SC ABA treatment on PROs (activities of daily living [ADL] limitation questionnaire of parent/caregiver, childhood HAQ [CHAQ]-DI, and parent global assessment of overall pt well-being [PaGA]) in 6-17-year pts with active pJIA in a Phase III trial (NCT01844518). Methods: Pts with pJIA aged 2-17 years with an inadequate response/intolerance to $>1$ DMARD were enrolled in this single-arm, open-label study and received SC ABA weekly for 4 months based on body weight tier $(10-<25 \mathrm{~kg}[50 \mathrm{mg}$ ABA], 25-50 kg [87.5 mg ABA] and $>50 \mathrm{~kg}$ [125 mg ABA]). JIA-ACR 30 criteria (ACR Pediatric 30 ) responders at Month 4 could receive ABA for another 20 months. For the 6-17-year cohort reported here, ADL limitation questionnaire of parent/caregiver (mean [SD] number of days [D] of parental/caregiver missed activity, paid care and missed school [absolute values per month and percentage of $D$ missed per month relative to an assumed average of 20 school $D /$ month]); CHAQ-DI (0-3 scale across 8 domains of disability component); and PaGA (0-100 $\mathrm{mm}$ visual analogue scale) were evaluated.

Results: Baseline characteristics of the 173 pts with pJIA from the 6-17-year cohort were: median (min, max) age, $13.0(6.0,17.0)$ years; median (min, max) number of active joints, $10.0(2.0,42.0) ; 78.6 \%$ of pts used MTX (median dose: $11.6 \mathrm{mg} / \mathrm{m}^{2} /$ week); and $26.6 \%$ were with prior biologic failure. All ADL limitation components improved from baseline to D113 (Month 4); these improvements were largely maintained at D309 (Figure). Relative percentage D missed from school decreased from 15\% (D1) to 5.5\% (D309, Figure D). CHAQ-DI and PaGA improved from baseline to D309 (Table). Further 2-year data are pending.

Table 1. CHAQ-DI and PaGA scores over time in the 6-17-year cohort

\begin{tabular}{lccccccc}
\hline & \multicolumn{7}{c}{ Day } \\
\cline { 2 - 8 } & $\begin{array}{c}1 \\
(\mathrm{n}=170)\end{array}$ & $\begin{array}{c}29 \\
(\mathrm{n}=170)\end{array}$ & $\begin{array}{c}57 \\
(\mathrm{n}=170)\end{array}$ & $\begin{array}{c}85 \\
(\mathrm{n}=167)\end{array}$ & $\begin{array}{c}113 \\
(\mathrm{n}=166)\end{array}$ & $\begin{array}{c}197 \\
(\mathrm{n}=144)\end{array}$ & $\begin{array}{c}309 \\
(\mathrm{n}=89)\end{array}$ \\
\hline CHAQ-DI & 0.99 & 0.82 & 0.73 & 0.63 & 0.61 & 0.52 & 0.46 \\
& $(0.69)$ & $(0.71)$ & $(0.65)$ & $(0.65)$ & $(0.64)$ & $(0.57)$ & $(0.56)$ \\
PaGA (mm) & 45.6 & 32.2 & 28.7 & 23.8 & 23.6 & 20.0 & 21.7 \\
& $(25.97)$ & $(24.56)$ & $(24.58)$ & $(23.59)$ & $(24.32)$ & $(23.04)$ & $(23.58)$ \\
\hline
\end{tabular}

Data are mean (SD). For CHAQ-DI (scale $0-3$ ) and PaGA (0-100 mm visual analogue scale),
higher scores indicate greater dysfunction and lower well-being, respectively.

Conclusions: In this analysis of patients with pJIA aged 6-17 years, SC abatacept demonstrated a beneficial effect on PROs including reductions in activity limitation and disability (CHAQ-DI) and improvement in well-being (PaGA) up to D309.

\section{References:}

[1] Lovell D, et al. Arthritis Rheumatol 2016;68(suppl 10): Abstract 948.

[2] Ruperto N, et al. Arthritis Care Res 2010;62:1542-51.

Disclosure of Interest: N. Ruperto Grant/research support from: The G. Gaslini Hospital has received contributions from the following industries for the coordination activity of the PRINTO network: Bristol-Myers Squibb, GlaxoSmithKline, Hoffman-La Roche, Novartis, Pfizer,sanofi-aventis, Schwarz Biosciences, Abbott, Francesco Angelini S.P.A., Sobi, Merck Serono, Consultant for: AbbVie, Amgen, Biogen Idec, Alter, AstraZeneca, Baxalta Biosimilars, Boehringer Ingelheim, Bristol-Myers Squibb, Celgene, Crescendo Bioscience, EMD Serono, Hoffman-La Roche, Italfarmaco, Janssen, Medlmmune, Medac, Novartis, Novo Nordisk, Pfizer, sanofi-aventis, Servier, Takeda, UCB Biosciences $\mathrm{GmbH}$, Speakers bureau: AbbVie, Amgen, Biogen Idec, Alter, AstraZeneca, Baxalta Biosimilars, Boehringer

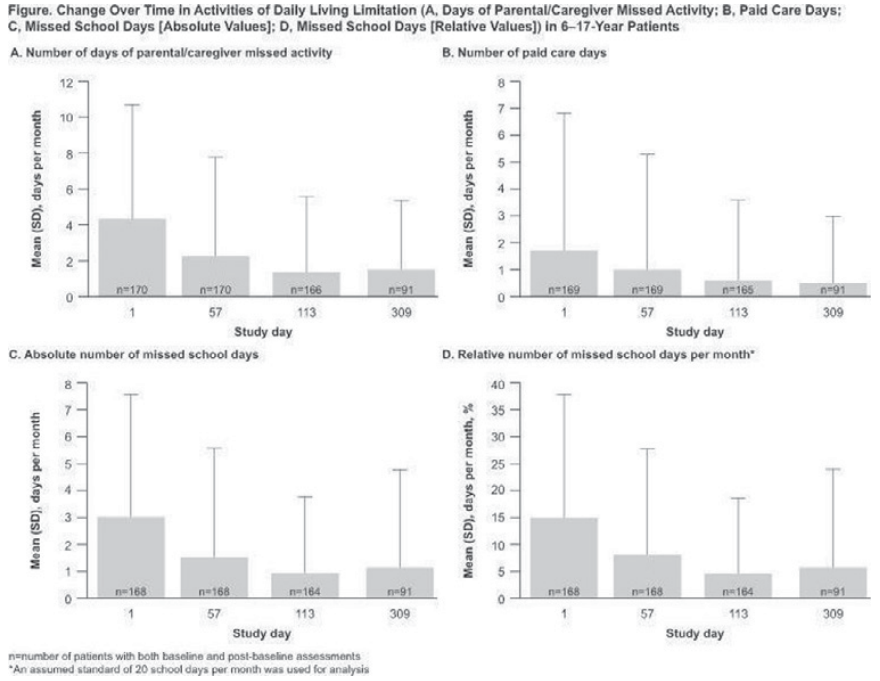

Ingelheim, Bristol-Myers Squibb, Celgene, Crescendo Bioscience, EMD Serono, Hoffman-La Roche, Italfarmaco, Janssen, Medlmmune, Medac, Novartis, Novo Nordisk, Pfizer, sanofi-aventis, Servier, Takeda, UCB Biosciences GmbH, H. Brunner: None declared, N. Tzaribachev: None declared, G. Vega-Cornejo: None declared, I. Louw: None declared, J. Anton Grant/research support from: Bristol-Myers Squibb, Novartis, Pfizer, AbbVie, GSK, Sobi, Roche, Alexion, Sanofi, Genzyme, Consultant for: Novartis, Sobi, Roche, Gebro, Pfizer, AbbVie, Alexion, Speakers bureau: Novartis, AbbVie, Pfizer, Sobi, Roche, Gebro, D. Viola: None declared, I. Foeldvari: None declared, V. Keltsev: None declared, D. Kingsbury: None declared, C. Wouters: None declared, B. Lauwerys: None declared, E. Alemao Shareholder of: Bristol-Myers Squibb, Employee of: Bristol-Myers Squibb, R. Wong Shareholder of: Bristol-Myers Squibb, Employee of: Bristol-Myers Squibb, M. Nys Shareholder of: Bristol-Myers Squibb, Employee of: Bristol-Myers Squibb, S. Banerjee Shareholder of: Bristol-Myers Squibb, Employee of: Bristol-Myers Squibb, A. Martini: None declared, D. Lovell Grant/research support from: National Institutes of Health, NIAMS, Consultant for: AstraZeneca, Bristol-Myers Squibb, AbbVie, Pfizer, Roche, Novartis, UBC, Forest Research Institute, Horizon, Johnson \& Johnson, Biogen, Takeda, Genentech, GlaxoSmithKline, Boehringer Ingelheim, Celgene, Janssen, Speakers bureau: Genentech

DOI: 10.1136/annrheumdis-2017-eular.2236

\section{OP0059 GOLIMUMAB VERSUS TOCILIZUMAB FOR SEVERE AND REFRACTORY JUVENILE IDIOPATHIC ARTHRITIS-UVEITIS. MULTICENTER STUDY OF 33 PATIENTS}

L. Domínguez Casas ${ }^{1}$, V. Calvo-Río ${ }^{1}$, I. Calvo $^{2}$, M. González-Fernández ${ }^{2}$, B. López-Montesinos ${ }^{2}$, M. Mesquida ${ }^{3}$, A. Adán ${ }^{3}$, M. Hernández ${ }^{3}, 0$. Maíz $^{4}$,

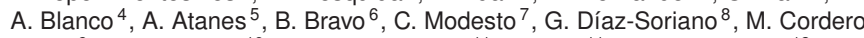
Coma $^{9}$, D. Díaz-Valle ${ }^{10}$, C. Fernández-Cid ${ }^{11}, \mathrm{~J}_{\text {. Cruz }}{ }^{11}$, O. Ruiz Moreno ${ }^{12}$, M. González-Vela ${ }^{1}$, R. Demetrio-Pablo ${ }^{1}$, N. Vegas-Revenga ${ }^{1}$,

C. Fernández-Díaz ${ }^{1}$, J. Hernández ${ }^{1}$, M. González-Gay $^{1}$, N. Palmou-Fontana ${ }^{1}$, R. Blanco ${ }^{1} .{ }^{1} \mathrm{HUMV}$, Santander; ${ }^{2} \mathrm{H}$ Fe, Valencia; ${ }^{3} \mathrm{H}$ Clinic, Barcelona; ${ }^{4} \mathrm{H}$, Donostia; ${ }^{5} \mathrm{HUAC}$, A Coruña; ${ }^{6} \mathrm{H}$ Nieves, Granada; ${ }^{7} \mathrm{H}$ V d'Hebron, Barcelona; ${ }^{8} \mathrm{H}$ Regional Universitario, Málaga; ${ }^{9} \mathrm{H}$, León; ${ }^{10} \mathrm{H} \mathrm{S}$ Carlos, Madrid; ${ }^{11} \mathrm{H}$, Pontevedra; ${ }^{12} \mathrm{H}$ Servet, Zaragoza, Spain

Background: Uveitis is a severe manifestation of Juvenil Idiopathic Arthritis (JIA). Anti-TNFa are recommended in refractory cases, mainly infliximab (IFX) or adalimumab (ADA) (Levy-Clarke et al. Ophthalmology 2014; 121: 785-796). However, sometimes they are ineffective, contraindicated or not tolerated. The next therapeutic step is not defined.

Objectives: To compare the efficacy of Golimumab (GLM) and Tocilizumab (TCZ) in related AlJ uveitis refractory to conventional immunosuppressive drugs and anti-TNF $\alpha$.

Methods: Multicenter study of 33 patients with uveitis associated-JIA. They were refractory to conventional treatment with high dose of corticosteroids and at least a) one conventional immunosuppressive drug and b) one anti-TNFa. For this reason it was decided to iniciate TCZ or GLM. TCZ was used in 25 patients: $8 \mathrm{mg} / \mathrm{kg} / 4 \mathrm{w}$ iv $(\mathrm{n}=21), 8 \mathrm{mg} / \mathrm{kg} / 2 \mathrm{w}(\mathrm{n}=2) ; 8 \mathrm{mg} / \mathrm{kg} / 8 \mathrm{w}(\mathrm{n}=1)$ and $2.9 \mathrm{mg} / \mathrm{kg}$ $\mathrm{sc} / \mathrm{w}(\mathrm{n}=1)$. GLM was used in 8 patients $(50 \mathrm{mg} / \mathrm{sc} / \mathrm{month})$. We assessed visual acuity (VA), degree of intraocular inflammation, vitreous inflammation and macular thickening (with OCT). Quantitative variables were expressed with mean \pm SD or median [IQR], according to its distribution. They were compared with the Student $t$ or the Mann-Whitney U test, respectively. Dichotomous variables were expressed as percentages and compared by the chi-square test.

Results: We studied 33 patients/61 affected eyes. There were no significant differences between TCZ and GLM at baseline in sex (o $/ \circ ; 4 / 21$ vs $3 / 5 ; p=0.19$ ), mean age $(18.5 \pm 8.3$ vs $19.9 \pm 8.7 ; p=0.55)$, positive ANA (95\% vs $100 \%$; $\mathrm{p}=0.7)$, uveitis duration before TCZ or GLM onset (116.4 \pm 93.6 vs $142.3 \pm 74.7$ 